\title{
O USO DE FILMES DE FICÇÃO COMO RECURSOS PEDAGÓGICOS OU "VER POR MEIO DE UMA GRAMÁTICA DESCONHECIDA"
}

\author{
L. A. OLIVEIRA, J. P. GONÇALVES* \\ Programa de Pós-Graduação em Educação da Universidade Federal de Mato Grosso do Sul \\ josiane.peres@ufms.br*
}

Submetido 30/07/2016 - Aceito 16/09/2018

DOI: $10.15628 /$ holos.2018.4899

\section{RESUMO}

Filmes dos mais variados tipos são utilizados como recursos didáticos por professores das mais variadas etapas e modalidades de ensino. Com relação ao uso de filmes de ficção, especificamente, alguns estudiosos relatam um uso instrumental destes recursos didáticos, um uso que não reconhece ou valoriza as qualidades estéticas dos filmes, suas características artísticas. Por essa razão, este estudo pretendeu compreender a relação entre professores(as) de um curso de Pedagogia e o uso de filmes, especialmente os de ficção, como recursos didáticos no ensino superior. A pesquisa qualitativa utilizou como instrumento questionários eletrônicos compostos de questões abertas e fechadas, ao qual professores(as) de um curso de Pedagogia responderam. Em sua heterogeneidade, os dados indicaram que dentre os professores que utilizam filmes como recursos didáticos, a maioria privilegia os filmes de ficção. Ao utilizá-los, os professores preocupam-se em estabelecer elos entre seus temas e os conteúdos das disciplinas que ministram, porém não foi identificada uma profundidade ou objetivo de exploração de aspectos estéticos dos filmes ou tentativas de traduzir sensibilidade em julgamento estético. O conhecimento da linguagem cinematográfica nem sequer foi considerado um pré-requisito para o uso dos filmes como recursos didáticos.

PALAVRAS-CHAVE: Cinema, filmes, recursos didáticos, linguagem cinematográfica.

\section{THE USE OF FICTIONAL FILMS AS TEACHING RESOURCES OR "TO SEE THROUGH AN UNKNOWN GRAMMAR"}

\begin{abstract}
Teachers of different educational stages and modalities use various kinds of films as didactic resources. With regard to fictional films using, particularly, some researchers report an instrumental using of these didactic resources, an using that doesn't recognize and valorize their artistic and aesthetic qualities. Therefore, this work aims to understand the relation between teachers of a faculty of Education and the use of films (particularly fictional films) as didactic resources in higher education. The qualitative research used electronic questionnaires with open and closed
\end{abstract}

questions which the teachers of a faculty of Education answered. Mixed results indicate that among the teachers who use films as didactic resources, the most choose to use fictional films. By using them, the teachers focus on establish links between the themes and contents of disciplines that they teach. However, it was not identified a depth or purpose of exploitation of films' aesthetic qualities that at least try to translate sensibility to aesthetic judgment. The knowledge of film language was not even considered as a precondition to using fictional films as didactic resources.

KEYWORDS: Cinema, movies, didactic resources, film language. 


\section{INTRODUÇÃO}

A contemporaneidade é cercada por imagens vindas de plataformas inimagináveis algumas décadas atrás. O uso de imagens em "movimento", especificamente, dos filmes como recursos audiovisuais com finalidades didáticas acompanha a história do cinema, mas populariza-se com a facilidade que os avanços tecnológicos promoveram na exibição e distribuição de vídeos das mais variadas durações.

Do mesmo modo como quando utilizam quaisquer outros recursos didáticos, os professores precisam de conhecimentos básicos ou essenciais para a manipulação e melhor aplicação de recursos audiovisuais. Nesse sentido, dizer que o trabalho com filmes não se reduz a exibi-los apenas para "passar o tempo de aula" implica dizer, contrariamente, que há modos recomendáveis e indicados de se desenvolver atividades educativas com essas ferramentas.

A tímida (mas crescente) produção científica brasileira voltada ao diálogo entre cinema e educação sugere abordagens instrumentais do cinema em sala de aula, sejam elas na educação básica ou no ensino superior. Abordagens desse tipo desconsideram os filmes como peças do cinema que possuem características próprias, que constituem uma unidade de certo modo independente e um concebimento estético, além de um contexto cultural e social como produtos culturais que são. A estética, por outro lado, é também algo passível de análise e sua presença aliada a objetivos educacionais em todas as etapas da educação já não é novidade, e nem deve ser, especialmente nos cursos de Pedagogia, que formam justamente profissionais que podem lidar com a ludicidade, o jogo, a brincadeira e manifestações artísticas de variados tipos.

Por essa razão, este trabalho objetivou compreender a relação entre professores(as) de um curso de Pedagogia e o uso de filmes, especialmente os de ficção, como recursos didáticos no ensino superior, justamente para observar se há indícios de uma valorização ou exploração estética dos filmes. A pesquisa qualitativa realizou-se utilizando questionário eletrônico e sua fundamentação teórica baseou-se em autores reconhecidos por seus trabalhos em cinema e em cinema e educação.

\section{MONTAGEM: CINEMA, CIÊNCIA, ARTE E EDUCAÇÃO}

Uma pessoa o vê na televisão ou na internet, talvez num daqueles inúmeros anúncios enfadonhos que às vezes impossibilitam a leitura, ou talvez antes de iniciar um vídeo no YouTube. Mas ela pode tê-lo visto em tantos outros lugares, em tantas outras plataformas. Talvez um amigo tenha indicado o filme e até feito um convite para assisti-lo. Talvez tenha apenas enviado um link. O anúncio visto pode ter sido o pôster do filme, ou um trailer, ou até mesmo imagens em movimento, mas sem som. Às vezes a pessoa apenas vai ao shopping center - onde ficam as mais populares salas de cinema no Brasil - e lá escolhe o filme ou gênero que mais lhe agrada.

Essa pessoa pode ter comprado pipoca antes de assisti-lo, ou um refrigerante. Talvez ela precise pegar óculos na entrada para assistir filmes em 3D. Talvez ela não precise ir à sala de cinema, talvez ela assine o Netflix ${ }^{1}$ ou tenha uma enxurrada de canais de televisão ocupadas

\footnotetext{
${ }^{1}$ Empresa e serviço de streaming por assinatura estadunidense por meio do qual é possível assistir audiovisuais variados
} 
especial ou exclusivamente com filmes.

Quando começar o filme ela assistirá uma história que contém um enredo, na maioria das vezes diálogos, poderá ser uma animação, poderá conter atores e/ou cenários reais, provavelmente as imagens serão coloridas. Os atores estarão atuando. O espectador assistirá cenas. Essas cenas foram filmadas utilizando diversas técnicas. Todo o filme precisou de uma articulação de técnicas que compõem a linguagem cinematográfica, tal articulação nos permite entender as histórias dos filmes, nos envolvermos, acreditar que aquilo é real e ao mesmo tempo saber que não é real. As cenas foram filmadas, editadas, montadas. Cores, direção, roteiro, figurino, edição/montagem, som, atuação. Nem sempre conseguimos pensar em todos esses elementos quando assistimos aos filmes e como se não bastasse há muito mais além. Esses momentos em que vivemos a experiência do cinema, a ilusão de ótica, demandam muito mais.

Gostos, desejos, publicidade, pessoas e/ou firmas nacionais e estrangeiras que fazem e/ou investem dinheiro em filmes, firmas distribuidoras responsáveis por encaminharem os filmes aos donos das salas de cinema, os donos das salas de cinema que cobram para as pessoas sentarem-se numa poltrona por um determinado período de tempo e assistirem imagens em movimento, censura, dublagem, legendas. São inúmeros os exemplos apontados por Bernardet (2011), autor empenhado em demonstrar que o cinema, embora muitas vezes possamos reduzi-lo ao filme que assistimos, ou pior, à história presente naquilo que assistimos, é muito mais do que isso: é arte, é produto, carrega ideologias, é instrumento e produto de uma complexa máquina internacional da indústria, comércio e controle cinematográficos ${ }^{2}$. E mais. Mais o suficiente para tornar a atividade de definir cinema uma tarefa difícil, complexa.

\begin{abstract}
Sobre o cinema podemos dizer muitas coisas: que é técnica, indústria, arte, espetáculo, divertimento, cultura. Depende do ponto de vista do qual o consideramos. Cada um deles é igualmente fundamentado e não pode ser negligenciado. Mas se considerarmos o cinema como um todo, através da interação de seus vários aspectos, saímos do campo das definições e entramos no da observação. E observaremos então que o cinema é aquilo que se decide que ele seja numa sociedade, num determinado período histórico, num certo estágio de seu desenvolvimento, numa determinada conjuntura política-cultural ou num determinado grupo social (Costa, 2003, p. 28).
\end{abstract}

Dada sua complexidade, é justificável, portanto, que um olhar científico seja destinado ao cinema para que este seja melhor analisado e compreendido. Aliás, a ciência possui um papel importante na história do cinema.

De acordo com Costa (2006), antes de inaugurar uma era de predominância das imagens no início do século XX, o cinema apareceu por volta de 1895, quando não possuía um código próprio e estava misturado a outras formas culturais, como: espetáculos de lanternas, teatro popular, cartuns, revistas ilustradas, cartões-postais. Além disso, os aparelhos responsáveis pelas projeções eram exibidos como novidades nos círculos de cientistas, por exemplo, além de outras exposições associadas ao divertimento popular.

Quando George Méliès (ilusionista francês que dominou a produção de filmes nos primeiros anos da história do cinema, um dos precursores do cinema, considerado "pai dos efeitos especiais") conversou com Lumière (um dos inventores do cinema) buscando adquirir um

(filmes de ficção, documentários, animações, etc.) em plataformas que suportem conexão com internet.

${ }^{2} \mathrm{~A}$ introdução deste tópico é uma referência proposital ao trabalho de Bernardet (2011) em que ele se lança ao desafio de explicar o que é cinema. As adaptações são, na realidade, atualizações necessárias devido às inovações tecnológicas que permitem novas formas de assistir filmes e novos contatos com a linguagem audiovisual. 
cinematógrafo, Lumière o desencorajou, afirmando que aquele aparelho não tinha futuro como espetáculo, que tratava-se de um instrumento científico para reproduzir movimentos e que serviria apenas para pesquisas (Bernardet, 2011). Nesse mesmo dia, 28 de dezembro de 1895, os irmãos Lumière fizeram a primeira exibição pública de filme mais popular da história do cinema, embora não seja a primeira, pois a invenção do cinema também está ligada ao americano Thomas $A$. Edson que já havia feito progresso desde que patenteou uma máquina chamada quinetoscópio entre 1893 e 1895 (Costa, 2006).

Para Bernardet (2011), é possível que a impressão de realidade seja a base para o grande sucesso do cinema, a imagem cinematográfica permite-nos assistir a fantasias como se fossem verdadeiras, de modo a conferir-lhes significado. $O$ autor relembra que reproduzir a realidade é um anseio antigo compartilhado por artistas e cientistas. A busca para criar a imagem em movimento desenvolve-se no século XIX no meio científico. Até a criação de máquinas como cinematógrafo no final deste mesmo século, cientistas tentaram criar, por exemplo, uma "câmerarevólver" para registrar a passagem de Vênus pelo Sol, um complexo equipamento com vinte e quatro câmeras para analisar o galope de um cavalo, e um "fuzil fotográfico" capaz de tirar doze fotos em um segundo usado para fotografar e analisar o voo de um pássaro.

Mesmo que a ciência desempenhe um importante papel na origem do cinema, este também é fruto da indústria cinematográfica e arte, com linguagem e técnicas próprias, a sua gramática. Conhecer essa gramática permite uma maior compreensão dos filmes, das intencionalidades, da estética de sua criação, enfim, de tudo aquilo entre o criador e a ilusão ou impressão de realidade.

A linguagem cinematográfica é, na verdade, formada por diferentes linguagens, todas subordinadas a um meio. O filme pode agregar em si todas as outras artes: fotografia, pintura, teatro, música, arquitetura, dança e, claro, a palavra falada. Tudo pode chegar ao cinema - grande ou pequeno, natural ou fantástico, bonito ou grotesco (Edgar-Hunt, Marland \& Rawle, 2013, p. 11).

A rica linguagem criada pela gramática cinematográfica articula códigos e elementos distintos: imagens em movimento, luz, som, música, fala, textos escritos (DUARTE, 2009). As infinitas possibilidades de produzir significados dependem do modo como serão combinados e montados "luz e sombra, velocidade da câmera, captura dos espaços, ângulos de filmagem e, acima de tudo, da sequência temporal em que os planos (imagens entre dois cortes) são organizados na montagem" (p. 33).

Assim como outras manifestações artísticas, o cinema também embrenha-se em momentos, movimentos, escolas, tendências, e portanto, recebe classificações comuns (de acordo com suas características) que superam os gêneros drama, comédia, ficção científica, ação, aventura, por exemplo, que são classificações largamente utilizadas pelo público.

Muitos autores ocupam-se da classificação dos momentos estéticos do cinema, tanto teóricos desta arte quando autores que a desbravam mesmo na área da educação. Assim, os autores falarão de impressionismo francês, expressionismo alemão, surrealismo, Nouvelle Vague, entre outros (Costa, 2003; Mascarello, 2006; Duarte, 2009; Bernardet, 2011).

Cada movimento representa uma tendência ou característica significativa do cinema. Duarte (2009), por exemplo, aponta a importante inovação trazida pelo expressionismo alemão:

Entre 1920 e 1930, a Alemanha dá uma vigorosa contribuição ao desenvolvimento da linguagem 
cinematográfica: a partir de um roteiro escrito por Hans Janowitz e Carl Mayer, Fritz Lang dirige $O$ gabinete do Dr. Caligari (1919), marco do nascimento de um movimento que faria com que o cinema passasse a ser visto como arte: o expressionismo alemão. Rompendo com os parâmetros narrativos da época, os expressionistas criaram uma cinematografia da vida interior, uma espécie de tradução em imagens, do mundo subjetivo. (p. 26)

Envolver-se com os filmes é tarefa fácil mesmo para quem por ventura não tenha conhecimentos sobre sua linguagem característica. Entendê-los melhor, compreendê-los e especialmente analisá-los eficientemente, entretanto, exige um conhecimento básico de sua gramática. Ao utilizar o cinema como recurso didático, os professores podem aproximar novamente o cinema arte do cinema ciência, âmbito onde também surgiu e se desenvolveu, e além disso, proporcionar necessários momentos de apreciação e conhecimento estético. Para Araújo (2018), historicamente o cinema foi utilizado como uma ferramenta de aprendizagem e de conscientização em relação a alguns conteúdos educativos.

Há mais de duas décadas, professores de todas as partes popularizaram o uso de filmes como apoio a suas aulas (Christofoletti, 2009). Se antes da década de 1970 os filmes (de curta, média e longa-metragem) estavam confinados a circuitos de exibição e às programações dos canais de televisão, com a tecnologia de gravação de audiovisuais em meios magnéticos e a reprodução de fitas, criou-se o mercado do vídeo doméstico, expandindo o alcance do cinema e tornando-o uma mídia praticamente onipresente. Como afirma Christofoletti (2009, p. 604) "de fitas de VHS ou em DVDs, da sala de casa para a sala de aula, foi um pulo". Notando que os filmes poderiam servir de apoio pedagógico para as disciplinas, os professores utilizaram os aparatos tecnológicos acessíveis de modo a tornar os conteúdos mais atraentes se comparados às tradicionais aulas expositivas. Conforme Leandro (2016), o cinema é importante no contexto de sala de aula, por se caracterizar como um instrumento de promoção de valores e de cidadania, além de contribuir com a reflexão e promoção da criatividade dos alunos.

Além da sala de aula, no âmbito da educação aumenta o número de pesquisadores que investigam os filmes. Christofoletti (2009) cita vários estudos e usos da relação cinema e educação resultantes dessas investigações: há pesquisadores que quando fazem análise fílmica aproximamse mais da análise literária do que dos elementos característicos dos filmes, aspectos visuais e sonoros próprios às teorias contemporâneas do cinema; há um bom número de estudos que relacionam infância e cinema; há estudos sobre cinema e diversidade cultural; há estudos que defendem os filmes como signos mediadores com potencial para o desenvolvimento críticoreflexivo dos professores (Mayrink, 2007); outros pesquisadores destacam o uso do cinema como documento histórico e como recurso didático para uma aprendizagem dialógica, significativa e crítica da disciplina de História, permitindo inclusive a formação da consciência histórica; vários autores se ocupam de análises descritivas de filmes, popularizadas por Christian Metz.

Bernardet (2011) faz uma interessante analogia relacionando produção de filmes e a atividade reflexiva e analítica, cerne da produção científica, logo, do trabalho de pesquisadores. 0 autor caracteriza a filmagem como um ato de recortar o espaço, de determinado ângulo, em imagens, com uma finalidade expressiva. Nesse sentido, filmar é uma atividade de análise que envolve escolhas, perspectivas, objetos. No momento de composição do filme, as imagens filmadas são colocadas umas após as outras. Para o autor, essa reunião de imagens, a montagem, é então uma atividade de síntese, pois para que haja a edição é necessária a seleção e adequação das partes que comporão o todo. 
Fundamentada numa argumentação que defende o filme como um instrumento adequado para o exercício da reflexão (devido às escolhas que sua produção opera, os elementos que organiza entre si, as possibilidades de refletir ou ocultar o real), Mayrink (2007) apresenta alguns pontos favoráveis do uso de filmes como recursos pedagógicos no processo de formação de professores.

O filme [...] além de ser uma ferramenta com a qual o aluno tem familiaridade, pode trazer à tona elementos para discussão que são relevantes para a prática pedagógica dos professores em formação, já que possui a capacidade de construir um mundo que mantém relações complexas com o mundo real da sala de aula. Considerado desta forma, o filme pode despertar um olhar reflexivo dos professores em formação sobre semelhanças ou diferenças entre a realidade de sala de aula vivida por eles e aquela apresentada na tela; porém, o faz de uma maneira mais distanciada, sem um envolvimento pessoal direto que gere análise ou crítica de sua própria ação (p. 36).

Além do aspecto reflexivo, aliás, aliado a este, há autores que defendem o uso dos filmes como recursos didáticos de modo a possibilitar uma educação estética, o contato com a arte e o desenvolvimento de "impulsos lúdicos" tanto na educação básica (Duarte \& Alegria, 2008) quanto no ensino superior (Moraes, 2013).

No campo da produção científica em educação ou mesmo nas salas de aula, é importante que o trabalho com os filmes considere-os como peças que são (também) artísticas. Portanto, é necessário que suas características estéticas não sejam ignoradas para que análises profundas, contextualizadas, satisfatórias e eficientes sejam realizadas. É igualmente necessário que sejam reconhecidas as suas finalidades de entretenimento e conhecimento e a importância dos filmes selecionados pelos professores/pesquisadores no panorama do cinema local ou mundial.

É nesse sentido que Duarte (2009), reconhecendo o cinema como uma das artes visuais mais importantes da atualidade, sugere algumas atitudes para que os ambientes escolares contribuam para a formação estética dos espectadores, de modo que sejam capazes de elaborar julgamento estético. Para a autora, o papel da escola nesse processo é favorecer o encontro de espectadores com bons filmes, ou seja, filmes que possuem: reconhecido valor artístico e cultural; roteiros bem elaborados e filmados; densidade e complexidade que caracterizam as obras-primas, tornadas clássicas pela história e durabilidade. De acordo com Duarte, encontros desse tipo, parecidos com os das mostras e festivais de cinema, contribuem para a "quebra" da lógica do gosto resultante da relação (quase) exclusiva com filmes de um mesmo padrão estético e narrativo como é o padrão do cinema hollywoodiano, hoje hegemônico no mercado mundial.

Proporcionar o contato com grandes obras do cinema não é tudo, entretanto. Duarte alerta para a importância de ensinar a analisar e julgar os filmes, isso sem que o professor imponha seus critérios de gosto. É necessário que haja políticas públicas destinadas a favorecer o acesso, em salas de projeção, a obras reconhecidas por sua qualidade, a uma seleção que garanta diversidade estética, narrativa, geográfica e cultural. Finalmente, a autora afirma que é necessário proporcionar o contato com conhecimentos da linguagem cinematográfica para que se desenvolva a habilidade de traduzir sensibilidade em julgamento estético. Em outras palavras, ela defende uma imersão na linguagem cinematográfica para que os filmes sejam julgados adequada e satisfatoriamente.

Esta pesquisa limita-se ao uso dos filmes de ficção (produtos do cinema), especificamente, como recursos didáticos no ensino superior num curso de Pedagogia, ou seja, num curso de formação de professores. De qualquer forma, considera coerentes e válidas todas as sugestões de 
Duarte (2009), anteriormente citadas, que podem e até são originalmente pensadas considerando principalmente estudantes da educação básica.

\section{METODOLOGIA (OU MAKING OF)}

Esta pesquisa de caráter qualitativo objetivou adotar como sujeitos os(as) onze professores(as) do curso de Pedagogia do campus investigado (campus de Naviraí da Universidade Federal de Mato Grosso do Sul), entretanto, apenas seis professores(as) testaram o instrumento utilizado: questionários em formato de formulário eletrônico. A preferência pelos professores do curso de Pedagogia justifica-se por ser esperada dessa área a maior e até melhor preocupação com a utilização e estudo de recursos pedagógicos, além das demandas com relação à educação estética que (provavelmente) encontrarão os professores em formação no exercício da profissão.

De acordo com Gil (2008), esta pesquisa classifica-se como descritiva.

As pesquisas deste tipo têm como objetivo primordial a descrição das características de determinada população ou fenômeno ou o estabelecimento de relações entre variáveis. São inúmeros os estudos que podem ser classificados sob este título e uma de suas características mais significativas está na utilização de técnicas padronizadas de coleta de dados (p. 28).

Disponível online por mais de um mês em endereço eletrônico enviado aos sujeitos da pesquisa, o formulário encaminhado aos professores do curso de Pedagogia possuía dez questões, sendo seis delas fechadas e quatro abertas. As questões buscaram descrever/caracterizar a relação dos professores do curso com a utilização dos filmes como recursos (pedagógicos) audiovisuais, com atenção especial aos filmes de ficção, seja na rotina da sala de aula ou em sua própria formação quando relacionada à oportunidade de aprendizagem do uso de tais recursos.

Nesse sentido, as três primeiras questões buscaram identificar o uso dos filmes como recursos pedagógicos, a frequência do uso e os tipos de filmes utilizados. As próximas três questões buscaram identificar a relação dos professores com o conhecimento da linguagem cinematográfica e envolveram o posicionamento dos professores com relação à necessidade desse conhecimento específico, bem como uma autoavaliação com relação à presença desses conhecimentos em suas trajetórias acadêmicas.

As questões (dissertativas) restantes buscaram identificar aspectos mais específicos da prática dos professores com relação aos filmes, bem como suas opiniões com relação ao uso dos filmes de ficção, especificamente, como recursos pedagógicos. Em resposta à sétima questão os professores citaram exemplos de filmes utilizados em suas aulas, à oitava questão expuseram suas opiniões com relação ao uso de filmes de fiç̧ão como recursos pedagógicos; à nona questão responderam quais aspectos dos filmes são normalmente privilegiados em suas práticas pedagógicas; e, à décima questão, mencionaram dificuldades com relação ao uso dos filmes.

De acordo com Gil (2008, p. 121), a construção do questionário consiste em "traduzir os objetivos da pesquisa em questões específicas" e "as respostas a essas questões é que irão proporcionar os dados requeridos para descrever as características da população pesquisada". Desse modo, convencionou-se utilizar o questionário como instrumento já que uma preocupação prioritária da pesquisa foi conhecer (e de certo modo, descrever) a relação dos professores do curso de Pedagogia com o uso dos filmes no ensino superior.

Uma busca rápida no banco de teses da Coordenadoria de Aperfeiçoamento de Pessoal do 
Nível Superior (CAPES), além de outros sites destinados à divulgação científica, revela que são nas áreas de Administração e Economia que as pesquisas voltadas ao uso dos questionários eletrônicos são mais presentes. Em Educação, estabelecendo uma comparação, a quantidade de estudos é quase inexpressiva. Um dos estudos da área de Administração relacionado ao marketing, por exemplo, estabelece vantagens da utilização dos questionários eletrônicos como instrumentos, dentre elas: alcance global, flexibilidade, alcance de tempo, faculdade de coleta e tabulação de dados, baixo custo, simples obtenção de grandes amostras, alto controle sobre o preenchimento da pesquisa, preenchimento obrigatório de perguntas (Gonçalves, 2008). Outro estudo voltado à Psicologia da Educação, até mesmo sugere o uso desse instrumento, justificando que erros cometidos na versão impressa podem ser controlados na versão eletrônica mediante programação adequada, além de não haver grandes dificuldades na resposta e a possibilidade de inserção automática das respostas em banco de dados (Omote, Prado \& Carrara, 2005).

Uma reflexão após a aplicação do instrumento de pesquisa, entretanto, levantou a hipótese de que se os questionários fossem impressos talvez a participação dos professores na pesquisa fosse maior e supõe-se que a relativamente baixa participação pode ser uma consequência de uma possível falta de familiaridade com questionários aplicados por meio da internet.

Hill e Hill (2005), além de Gil (2008), afirmam que as questões dos questionários são orientadas de modo a indicarem os objetivos das pesquisas. No caso desta pesquisa, as questões buscam identificar, de acordo com a classificação dos autores acima citados: fatos (sem distanciálos de atitudes), no que se refere à realidades dos(as) professores(as) com relação ao uso dos filmes em suas aulas; e opiniões, igualmente referente ao uso dos filmes como recursos pedagógicos no ensino superior.

A análise dos dados partiu das respostas inicialmente sistematizadas pelo Google Form em gráficos e listas de respostas e caminhou em direção à redução, apresentação e conclusão/verificação de dados, tal como proposto e sugerido por Miles e Huberman (1994) e reproduzido, bem como indicado por Gil (2008) e Alves-Mazzotti e Gewandsznajder (2000).

\section{RESULTADOS E DISCUSSÕES}

A descrição dos resultados a seguir não tem a pretensão de representar integralmente a realidade de todos os professores do curso de Pedagogia do campus em que o estudo foi realizado ou mesmo um grupo mais abrangente como o dos professores do curso de Pedagogia, de modo geral. Apenas 6 professores(as) responderam ao questionário eletrônico, número equivalente a pouco mais de $50 \%$ dos(as) professores(as) ao qual foi destinado. De qualquer forma, os dados não perdem sua validade, pois sabe-se ser inadequado aplicar critérios quantitativos de validade a dados que são (também) qualitativos (Richardson, 2012). Além disso, eles devem ser observados criticamente de modo que sua heterogeneidade e complexidade não sejam ignoradas ou desconsideradas.

Mas afinal, os/as participantes da pesquisa utilizam filmes como recursos didáticos em suas aulas no ensino superior? Apenas 2 professores/as sinalizaram não usar filmes como recursos didáticos em suas aulas no curso de Pedagogia. Do número restante $(66,7 \%)$, três professores/as afirmaram utilizar o recurso poucas vezes numa mesma disciplina e um afirmou utilizá-lo uma considerável quantidade de vezes numa mesma disciplina ministrada. Com relação aos tipos de filmes utilizados, identificou-se que nenhum dos professores utiliza documentários 
exclusivamente. A maior parte dos professores utiliza documentários e filmes de ficção $(33,3 \%)$, um/a dos/as professores/as utiliza apenas ficção e outros tipos de recursos audiovisuais. Identificamos portanto que, da amostra analisada, a maior parte dos professores utilizam os filmes como recursos didáticos com pouca frequência e quando os usam privilegiam os filmes de ficção em suas abordagens pedagógicas. Isso fica melhor evidenciado quando os(as) professores(as) citam as obras audiovisuais utilizadas em suas aulas: o número de filmes de ficção é substancialmente maior.

Para os(as) professores(as), o conhecimento da linguagem cinematográfica não deve ser um pré-requisito para que se use os filmes como recursos didáticos. A maioria deles(as) - 50\%, para ser mais exato - nem sequer acredita que conhecimentos da linguagem cinematográfica sejam necessários ou pré-requisitos para usar filmes nas aulas no ensino superior. No entanto, um/a dos/as professores/as acredita que possuir conhecimentos sobre a linguagem cinematográfica seja preferencial, e outros/as dois/duas professores/as acredita que mesmo que não seja pré-requisito, é necessário possuir conhecimentos da linguagem cinematográfica.

Christofoletti (2009), dentre outros autores (que o próprio cita, inclusive), reforça a importância do conhecimento cinematográfico, básicas noções de luz, câmera, enquadramento e ação e as múltiplas composições da montagem, por exemplo, pois às vezes as imagens se ligam em "fios invisíveis" (p. 605), fios responsáveis pela ilusão de ótica que são a impressão de realidade e a impressão de movimento (Bernardet, 2011; Metz, 2017). Sem esses conhecimentos somos facilmente iludidos pelas imagens na tela e podemos acreditar, por exemplo, que os vídeos re(a)presentam o movimento da vida, quando na verdade tudo não passa de fotografias imóveis (dezenas de fotogramas por segundo) projetadas nesse ritmo.

A montagem das cenas, os enquadramentos, a luz, enfim, os elementos que compõem a linguagem cinematográfica são manejados de acordo com as intencionalidades de quem produz os filmes. Conhecê-las, portanto, ajuda-nos a entender essas intenções e porquê somos de certo modo por elas afetados, auxilia-nos a promover um distanciamento necessário da imagem para analisá-la.

Compreender o cinema significa também aprender a tomar as devidas distâncias da imagem, para compreender os mecanismos de produção de sentido e, ao mesmo tempo, saber que são exatamente a distância da qual esta imagem provém e o distanciamento em relação a nossa experiência cotidiana, do universo em que nos coloca, que produzem a fascinação e que nos seduzem (Costa, 2003, p. 28).

Uma parcela expressiva dos(as) professores(as) - 83,3\% - não teve a oportunidade de aprender sobre linguagem cinematográfica durante sua trajetória de formação. Isso justifica a forma como eles(as) descrevem seus conhecimentos com relação a essa linguagem: metade afirma não conhecer ou conhecer pouco e o restante classifica seus conhecimentos como medianos. É perfeitamente possível que o fato de não possuírem conhecimentos específicos da linguagem cinematográfica justifique a maioria dos(as) professores(as) entenderem que esses conhecimentos não são pré-requisitos para o uso de filmes como recursos didáticos.

A heterogeneidade dos dados torna-se mais evidente nas questões discursivas. Ao citar exemplos de obras audiovisuais utilizadas em suas aulas, os(as) professores(as) indicam filmes de ficção, documentários, animações, filmes de ficção feitos para a televisão, documentários e programas de televisão cujo público-alvo são professores. O número de filmes de ficção é bem maior do que qualquer outro tipo de obra audiovisual e há um certo padrão entre os filmes 
citados: filmes do gênero drama, estadunidenses, na maioria das vezes com indicações a premiações que recebem os holofotes da mídia como Oscar (The Academy Awards) ${ }^{3}$ ou Emmy ${ }^{4}$, mas sem muito prestígio no âmbito da crítica especializada, como "The Wave", 1984, dirigido por Alexander Grasshoff ou "Mona Lisa Smile", 2003, dirigido por Mike Newell. Apenas dois filmes de ficção citados não são estadunidenses, um é brasileiro (Narradores de Javé, 2003, dirigido por Eliane Caffé) e outro é uma coprodução entre Itália, França e Alemanha (Der Name der Rose, 1986, dirigido por Jean-Jacques Annaud). Os dois filmes foram utilizados pelo/a mesmo/a professor/a, que além destes utilizou animações e filme estadunidense em várias disciplinas. Essa variedade do uso dos recursos audiovisuais supõe uma habilidade de adaptação de recurso didático para finalidades distintas.

Questionados sobre a importância da utilização de filmes de ficção como recursos didáticos, especificamente, mesmo os/as professores/as que não os utilizam levantaram dois pontos que devem ser destacados: o diálogo entre filmes e conteúdos das disciplinas; e o uso inadequado dessas ferramentas pedagógicas, quando o primeiro ponto não é considerado ou respeitado. Os excertos abaixo exemplificam os dois pontos.

Considero ser muito importante o uso de filmes, sendo ficção ou não, como recurso didático para o professor, desde que seja trabalhado com um propósito didático planejado e tenha relação com o conteúdo a ser discutido (Professor/a 1).

É importante, mas é preciso que o professor consiga fazer um elo da temática do mesmo (filme utilizado) e dos conhecimentos relacionados com a disciplina que ministra dentro de uma perspectiva científica e não apenas como passatempo ou com opiniões pessoais ou do senso comum que não acrescentam em nada ao conhecimento do aluno e ainda podem influenciar determinadas formas de pensar e/ou preconceitos (professor/a 2).

[...] O filme não é apenas para ser passado e pronto, acabou a aula. Ou passar o filme para terminar a aula mais cedo. Ao contrário, esse recurso precisa ser utilizado para potencializar a aprendizagem, suscitar discussões pertinentes e levar à construção do pensamento autônomo do sujeito (Professor/a 3).

Duarte (2009) apresenta objetivas e importantes considerações em "Cinema \& Educação". A autora classifica como excelente a articulação entre textos acadêmicos e textos fílmicos para "trabalhar temáticas complexas com estudantes de ensino médio e superior" (p. 74), pois essa atitude permite abordar um problema sob diversos aspectos e perspectivas. A autora até mesmo cita um exemplo bem sucedido de articulação entre filmes e ensino de filosofia que deu origem a um livro. De qualquer forma, essa articulação não pode ignorar os filmes como produtos do cinema, peças com qualidade estética e que embora não se encerrem nelas mesmas, não possuem apenas a finalidade de ilustrar algo.

Possuir os aparatos técnicos para reproduzir os filmes não significa que nós professores saibamos como fazê-lo satisfatoriamente, sustenta Duarte (2009). Não é unânime no meio educacional o reconhecimento do cinema como fonte de conhecimento. Embora cinema (também)

\footnotetext{
${ }^{3}$ Prêmio entregue a cineastas anualmente pela Academia de Artes e Ciências Cinematográficas, fundada em Los Angeles, Califórnia. Mais antiga cerimônia de premiação na mídia e mais midiática que todas. Alvo de muitas críticas, como por "esnobar" filmes com menor investimento, porém muito bons e mais recentemente por ignorar cineastas negros.

${ }^{4}$ Prêmio atribuído a programas e profissionais de televisão sobretudo estadunidenses, baseado no Oscar e, pelo grau de importância recebida, equivalente ao Oscar da televisão.
} 
seja arte, temos dificuldade de reconhecê-lo como arte, pois ele está fortemente associado à diversão e ao entretenimento, especialmente em comparação a "artes mais nobres", como a literatura, por exemplo. O cinema está culturalmente associado ao espetáculo de diversão, a maioria dos professores usa os filmes, portanto, como um "recurso didático de segunda ordem, ou seja, para 'ilustrar', de forma lúdica e atraente, o saber que acreditamos estar contido em fontes mais confiáveis" (p. 70).

Um uso adequado dos filmes como recursos didáticos, de acordo com a perspectiva defendida por Duarte (2009), considera: conhecer o filme antes da exibição em atividade pedagógica, recolher informações sobre o filme em questão e outros filmes do mesmo gênero, elaborar um roteiro de discussão que coloque em evidência os elementos para os quais se deseja chamar atenção; valorizar os filmes como são, não apenas pelo uso que se faz deles; munir o público ao qual o filme se destina de referências que lhe permita identificar o contexto em que o filme foi produzido, tais como país de origem, língua de origem, nome do diretor acompanhado de dados biográficos, ano de lançamento, premiações, repercussão, significado do filme em questão para o cinema local e/ou mundial, se o filme é considerado clássico, inovador do ponto de vista técnico ou temático, se é fundador ou integra uma escola ou movimento cinematográfico; além de conhecer pelo menos um pouco de história e teoria do cinema, pois filmes não são "decalques ou ilustrações para 'acoplarmos' aos textos escritos nem, muito menos, um recurso que utilizamos quando não podemos ou não queremos dar aula" (p. 75). Segundo Duarte (2009), usar narrativas fílmicas, narrativas que falam, descrevem, formam e informam, demanda saber como elas fazem isso.

Apenas um/a dos/as professores/as destacou aspectos que mais se aproximam do desenvolvimento de impulsos lúdicos em sua resposta. Para o/a professor/a em questão, os filmes de ficção podem "resgatar alguns valores, conceitos de vida, resgatar algumas emoções e também a imaginação nas aulas" (Professor/a 2). Os professores direcionaram as suas respostas de modo a indicar que os filmes de ficção não são peças soltas e desvinculadas do processo de aprendizagem, usá-los requer planejamento, preparação e objetivos claros. Eles não devem reforçar o senso comum e o uso deles está intrinsecamente ligado ao estabelecimento de relações com conteúdos abordados, de modo a ilustrá-los ou problematizá-los.

Moraes (2013), numa abordagem fundamentada em Schiller (filósofo alemão) e em tópicos das Diretrizes Curriculares Nacionais para os cursos de Pedagogia, argumenta ser não só importante, mas fundamental a construção de impulsos lúdicos e de uma educação estética na universidade, especialmente voltada para professores pedagogos em formação. Para que essa educação ocorra são necessários - além de professores formadores conscientes da importância da educação estética - investimentos financeiros e materiais e um contexto político-pedagógico favorável. De acordo com Moraes,

Sabe-se [...] o quanto a dimensão lúdica é intrínseca à educação - formal e informal - e como a escola, como espaço de educação formal legitimado socialmente, precisa estar atenta a essa dimensão na criança e esforçar-se para criar situações de valorização da mesma como base curricular. Além disso, tem-se claro que a arte se constitui como um elemento indispensável ao estímulo de dilatação dessa dimensão lúdica da criança, favorecendo a criatividade e a imaginação desta. Nessa perspectiva, a universidade como lócus de formação de pedagogos, não pode negligenciar seu papel no que tange à formação estético-artística desses profissionais, que atuam diretamente na escola. O pedagogo, entretanto, não precisa necessariamente se tornar um artista, mas possuir conhecimentos - amplo repertório - artístico e cultural a partir de experimentações, apreciações e análises estéticas e históricas sobre obras de arte. Com tal repertório, ele terá mais apropriação de elementos para mobilizar saberes referentes às artes na escola e em outros espaços 
educativos (p. 8).

A formação estética de estudantes de Pedagogia, de acordo com a autora, é essencial para o futuro exercício da profissão docente, pois aguçadas as sensibilidades criativas, artísticas e sensoriais desses profissionais por meio da arte, eles serão capazes de criar um arsenal amplo de ações pedagógicas e percepções diversas sobre as coisas que os envolvem, o que consequentemente resultará em "educadores mais antenados e sensíveis ao desenvolvimento das crianças e adolescentes" (p. 9). Considerando a possibilidade de que o contato com manifestações artísticas não seja tão presente no ensino superior, mesmo na formação de pedagogos, como idealiza Moraes e outros professores, devem ser ainda mais valorizadas as oportunidades de apreciação estética, como o trabalho com filmes supõe.

Apenas um/a professor/a cita o uso dos filmes como instrumento de avaliação, mas nenhum dos professores cita esta ferramenta como recurso didático principal, ou de fundamental importância no decorrer das disciplinas.

Os filmes servem para introduzir um novo conteúdo ou teoria, para problematizar ou melhor exemplificar os assuntos trabalhados, para propor novas discussões ou ampliar os pontos de vista sobre um mesmo tema, para finalizar discussões em forma de avaliação (com ou sem nota), entre outras (Professor/a 5).

Com relação aos aspectos dos filmes explorados pelos/as professores/as por meio da prática pedagógica, deve-se primeiramente considerar que apenas um/a dos professores/as que respondeu ao questionário teve a oportunidade de conhecer melhor aspectos da linguagem cinematográfica durante sua trajetória de formação. Desse modo, justifica-se a baixa ou pobre utilização de elementos específicos da linguagem cinematográfica para efeitos de análise e discussão ou a ausência, ao menos no discurso dos(as) professores(as), do objetivo de proporcionar o desenvolvimento de impulsos lúdicos e/ou exploração/educação estética.

Poucos professores citam clara e especificamente os aspectos explorados em sala, mas aparentemente, aqueles que usam os filmes como recursos didáticos aproveitam os temas dos filmes que são uma ilustração de conteúdos abordados em sala de aula e com estes tentam estabelecer elos. Esses temas, expressam-se nos filmes por meio de seus enredos e, portanto, obviamente pelos seus roteiros.

Um/a dos/as professores/as afirma que privilegia por meio de sua abordagem algumas cenas, posturas e comportamentos como alvos de reflexões. Nesse caso, além do enredo, o/a professor/a especifica (melhor), mesmo que indiretamente, um destaque para as atuações como fontes de análise em suas abordagens. Outro professor/a afirma buscar que os/as alunos/as percebam por meio das discussões as intencionalidades dos filmes, as intenções das falas, e diz privilegiar até mesmo a abordagem dos cenários. Nesse caso, percebe-se uma maior valorização não somente do tema ou do enredo, mas até mesmo da produção cinematográfica, de unidades de sentido que levam à composição final, o longa-metragem.

De acordo com as descrições dos(as) professores(as), as atividades com filmes consistem, basicamente, na exibição dos filmes em horário normal de aula e discussão em grupos menores e grandes grupos baseados ou não em questões norteadoras por eles(as) pré-formuladas. Deve-se considerar que o campus disponibiliza um pequeno auditório com projetor multimídia para a exibição de filmes, entre outras atividades. No auditório, destaca-se uma qualidade melhor de som. Já no laboratório de informática, raramente os acadêmicos do campus utilizam o áudio dos 
computadores o que impede na maioria das vezes a visualização de vídeos. Considerando a infraestrutura, a exibição dos filmes limita-se (com mais frequência) à sala de aula e ao auditório e a criatividade só pode se manifestar nas abordagens pedagógicas.

Um uso específico de recursos audiovisuais deve ser destacado por ser possivelmente uma particularidade dos cursos de formação em Pedagogia, ou em última análise, de licenciaturas, de um modo geral.

Não utilizo especificamente filmes em minhas aulas. Mas, como trabalho com metodologias do ensino, recorro mais a vídeos esporádicos que discutam e/ou abordem de forma clara e objetiva num curto espaço de tempo, os saberes e fazeres da Educação Infantil, da prática pedagógica e do ensino dos conteúdos escolares. Utilizo muito, com meus alunos, vídeos que ilustram determinados processos de ensino e aprendizagem, principalmente, na Matemática. Exemplo: situações em que o professor explora conceitos por meio de brincadeiras, questões do cotidiano da sala de aula em que a abordagem de um determinado conteúdo é explorado. Enfim, acabo recorrendo a trechos curtos de ações práticas em sala de aula. (Professor/a 3)

Como o excerto acima esclarece, o uso de recursos audiovisuais no curso de Pedagogia pode ser um grande aliado do processo de aprendizagem por ser capaz de apresentar, exibir, demonstrar situações de aprendizagem e de ensino por meio dos vídeos, situações essas que não são totalmente garantidas pelos estágios obrigatórios. Além disso, o professor pode utilizar esses recursos para apresentar situações particulares de ensino e aprendizagem, especialmente em disciplinas cujo enfoque é a metodologia de ensino.

Os/as professores/as não mencionaram nenhuma dificuldade com relação ao uso dos filmes, porém destacamos algumas de suas respostas. Um/a professor/a que não usa filmes como recurso didático disse que sua maior dificuldade seria a possibilidade de os alunos não se interessarem em estabelecer relações entre os filmes e os conceitos das disciplinas, algo que ele já viu acontecer no ensino superior e que empobrece as discussões de ambos. Outro/a participante, mesmo não citando nenhuma dificuldade, admite que se possuísse maiores conhecimentos de linguagem cinematográfica, as discussões enriqueceriam e os filmes seriam utilizados mais satisfatoriamente como recursos didáticos.

Certamente, como bem aponta o/a professor/a, um básico conhecimento de linguagem cinematográfica permite um maior afastamento de abordagens meramente instrumentais, que não valorizam os filmes em si, como arte, como concebimentos estéticos, mas como "ilustrações luminosas" (Duarte \& Alegria, 2008, p. 69) dos conhecimentos que consideramos válidos, ilustrações que vemos por meio dos filmes quando a atitude ideal seria olharmos diretamente para eles.

\section{CONSIDERAÇÕES FINAIS}

Durante a primeira exibição pública de filmes em 1895, Paris, os espectadores assustaramse quando viram a projeção de um trem vindo em sua direção. É difícil imaginar essa cena tendo nascido em meio a uma sociedade que veicula imagem (em cores e em movimento) em diversas plataformas, e é difícil justamente porque essa imersão faz com que aprendamos a ver os filmes da mesma forma que aprendemos a falar a língua nativa, observando pessoas mais experientes utilizá-la e participando desses momentos. Mesmo que aprendamos a falar presenciando as pessoas ao nosso redor, falar adequadamente e corretamente de acordo com padrões requer uma 
dedicação maior à gramática da língua, pois quanto maior o conhecimento desta, maior a possibilidade de empregá-la adequadamente e entendê-la correta e coerentemente.

Mesmo que cinema não seja língua, apresenta linguagem e sua linguagem apresenta gramática. Quanto mais se conhece a gramática presente nos filmes, mais se ampliam as possibilidades de entendê-los, e no caso da educação, de utilizá-los como recursos pedagógicos de modo adequado. A função dos filmes, entretanto, não é servir de instrumento pedagógico, assim como não são os livros de literatura infantil, as músicas, o teatro. Embora haja exercícios de transposição didática adequados, há também uma "didatização" da arte que aniquila seus valores estéticos. As produções artísticas não servem (apenas ou exclusivamente) ao ensino e à aprendizagem, elas servem à estética, ao belo, ao próprio fazer artístico.

Mesmo que nesta pesquisa os resultados tenham indicado uma coerente atitude de articulação entre conteúdos e temas de filmes, é necessário que nós professores olhemos para os filmes e não através deles por meio de uma gramática desconhecida, atitude que requer esquecermos por alguns momentos uma escola e uma universidade conteudistas. Olhar para eles implica conhecê-los esteticamente, valorizar suas características artísticas, conhecê-los profundamente de modo a superar a ilusão, propiciar e incentivar momentos de educação estética, especialmente no que diz respeito à formação inicial de pedagogos, pois dada a polivalência do professor da educação infantil e dos anos iniciais do ensino fundamental, por exemplo, um contato profundo com as artes e a ampliação do repertório cultural através da educação estética pode refletir qualitativamente na prática dos pedagogos e na aprendizagem de seus alunos.

\section{REFERÊNCIAS}

Araújo, Naiara Sales. (2018). Vargas, Franco e o cinema: a sétima arte, na Espanha e no Brasil, dos anos 40. Revista Livre de Cinema, Maranhão, 5(3), 101-118, set-dez, 2018.

Alves-Mazzotti, Alda Judith; Gewandsnajder, Fernando. (2000). O método nas ciências naturais $e$ sociais: pesquisa quantitativa e qualitativa. 2. ed. São Paulo: Pioneira.

Bernardet, Jean-Claude. (2011). O que é cinema. São Paulo: Brasiliense.

Christofoletti, Rogério. (2009). Filmes na sala de aula: recurso didático, abordagem pedagógica ou recreação? Educação UFSM ( Santa Maria), 34(3), 603-616. DOI: 10.5902/19846444

Costa, Antonio. (2003). Como compreender o cinema. 3. ed. São Paulo: Globo.

Costa, Flávia Cesarino. (2006). Primeiro cinema. In: Mascarello, Fernando. História do cinema mundial. Campinas: Papirus, p. 16-53.

Duarte, Rosália; Alegria, João. (2008). Formação estética audiovisual: um outro olhar para o cinema a partir da educação. Educação \& Realidade (Porto Alegre), 33(1),59-80.

Duarte, Rosália. (2009). Cinema \& Educação. 3. ed. Belo Horizonte: Autêntica Editora.

Edgar-Hunt, Robert; Marland, John; Rawle, Steven. (2013). A linguagem do cinema. Porto Alegre: Bookman.

Gil, Antonio Carlos. (2008). Métodos e técnicas de pesquisa social. 6. ed. São Paulo: Atlas.

Gonçalves, Daniel Infante Ferreira. (2008). Pesquisas de marketing pela internet: as percepções sob 
a ótica dos entrevistados. RAM. Revista de Administração Mackenzie, 9(7), 7088. https://dx.doi.org/10.1590/S1678-69712008000700004

Hill, Manuela Magalhães, Hill, Andrew. (2002). Investigação por questionário. 2. ed. Lisboa: Silabo.

Leandro, António Cruz. (2016). Cinema e cidadania: uma interação pedagógica em contexto escolar. Revista de Linguagem do Cinema e do Audiovisual, Rio de Janeiro, 2(1) 47-56, 2016.

Mascarello, Fernando (2006). História do cinema mundial. Campinas: Papirus.

Mayrink, Mônica Ferreira. (2007) Luzes... Câmera... Reflexão: formação inicial de professores mediada por filmes. Tese (Doutorado) - Curso de Linguística Aplicada e Estudos da Linguagem, Pontifícia Universidade Católica de São Paulo, São Paulo, Brasil.

Metz, Christian. (2017). A significação no Cinema. São Paulo: Perspectiva.

Miles, Matthew B; Huberman, A. Michael. (1994). Qualitative data analysis: an expanded sourcebook. Londres: SAGE Publications.

Moraes, Ana Cristina de. (2013). Educação estética na universidade e o constructo de impulsos lúdicos. In: 36⿳a ANPED, 2013, Goiânia. Sistema Nacional de Educação e Participação Popular: Desafios para as Políticas Educacionais. Goiânia: ANPED.

Omote, Sadao, Prado, Paulo Sérgio Teixeira do, \& Carrara, Kester. (2005). Versão eletrônica de questionário e o controle de erros de resposta. Estudos de Psicologia (Natal), 10(3), 397405. https://dx.doi.org/10.1590/S1413-294X2005000300008

Richardson, Roberto Jarry. (2012). Pesquisa social: métodos e técnicas. 3. ed. São Paulo: Atlas. 